\title{
MELHORAR O MUNDO, A ESCOLA E A SI PRÓPRIO: OS CAMINHOS ENTRECRUZADOS DA EXPERIÊNCIA JUVENIL
}

\author{
TO IMPROVE THE WORLD, THE SCHOOL AND THE SELF: \\ THE CRISSCROSSING PATHS OF YOUTH EXPERIENCE
}

\author{
MEJORAR EL MUNDO, LA ESCUELA Y EL SÍ MISMO \\ LOS CAMINOS ENTRECRUZADOS DE LA EXPERIENCIA DE LOS JÓVENES
}

Pedro Caetano ${ }^{1}$

\section{RESUMO}

O problema da apatia política, sobretudo dos mais jovens, constitui-se atualmente como uma séria ameaça à qualidade da democracia. À escola, como instância socializadora, é justamente pedido que trabalhe as competências críticas dos mais jovens, bem como as suas capacidades de subir em generalização, ajudando-os a ler o mundo. Contudo, o problema da apatia dos jovens estende-se às próprias atividades em comum realizadas em contexto escolar. O problema coloca-se tanto a uma escala macro como micro. Com vista a explorar as razões desta apatia, pretende-se dar conta neste artigo das tarefas que a educação pode ser chamada a desempenhar para a melhoria da democracia. Neste sentido, por meio do recurso a material empírico coletado em pesquisa em três escolas secundárias de Lisboa, mormente a partir de entrevistas semiestruturadas e observação de atividades promovidas pelos próprios estudantes, os resultados sugerem uma pluralidade de engajamentos e de relações com a política, correspondentes a uma diversidade de tarefas que a escola pode vir a desempenhar na formação política dos jovens. Assim, paralelamente à socialização política clássica, descortina-se o engajamento por individuação, caracterizado essencialmente pela participação na vida da escola e pela vontade de experimentação, e o engajamento por subjetivação, o qual se apresenta como uma problematização da política centrada no aperfeiçoamento de si próprio. Estes engajamentos, componíveis entre si, representam tanto diferentes formas de ser como quadros morais de avaliação e de ação. Eles dão conta de um domínio alargado da política enquanto experiência de relação com o mundo.

PALAVRAS-CHAVE: Política. Educação. Jovens. Ensino médio. Grande Lisboa. Processos de engajamento.

\section{ABSTRACT}

The problem of political apathy, especially among the younger ones, is a serious threat to the quality of democracy. The school, as a socializing forum, it is asked to work on the critical competences of the young, as well as their capacities to increase their judgements in generalization, helping them to read the world. However, the problem of apathy among young people extends to the activities in school context. The problem arises on both a macro and micro scale. In order to explore the reasons for this apathy, we intend in this article to give an account of the tasks that education can be called to play in order to improve democracy. In this sense, through the use of empirical research material collected in three secondary schools in Lisbon, mainly through semi-

\footnotetext{
${ }^{1}$ Doutor em - Sociologia da Cultura, do Conhecimento e da Educação - Faculdade de Ciências Sociais e Humanas da Universidade Nova de Lisboa (FCSH-Lisboa) - Lisboa, Portugal. Investigador Integrado do Centro Interdisciplinar de Ciências Sociais (CICS.NOVA). Faculdade de Ciências Sociais e Humanas da Universidade Nova de Lisboa (FCSH-Lisboa) - Lisboa, Portugal. E-mail: caepedro@gmail.com
}

Submetido em: 09 /10 /2017 - Aceito em: 07/01/2018

(C) ETD-Educação Temática Digital Campinas, SP $\quad$ v.20 $\quad$ n.2 $\quad$ p. $413-433 \quad$ abr./jun. 2018


structured interviews and observation of activities promoted by the students themselves, the results suggest a plurality of engagements and relations with politics, corresponding to a diversity of tasks that the school can play in the political formation of young people. Thus, in parallel with classical political socialization, we find the engagement by individuation, characterized essentially by participation in the life of the school and by the will of experimentation, and the engagement by subjectivation, as a problematization of politics centered on young's own self-improvement. These engagements, which can be combined together, represent different forms of being as moral frameworks of evaluation and action. They account for a broader domain of politics as an experience of relationship with the world.

KEYWORDS: Politics. Education. Young. High school. Great Lisbon. Engagement processes.

\section{RESUMEN}

El problema de la apatía política, especialmente entre los más jóvenes, es una seria amenaza para la calidad de la democracia. A la escuela, como foro de socialización, se le pide acertadamente que trabaje en las competencias críticas de los jóvenes, así como en sus capacidades para aumentar sus juicios de generalización, ayudándolos a leer el mundo. Sin embargo, el problema de la apatía entre los jóvenes se extiende a las actividades en el contexto escolar. El problema surge tanto a escala macro como micro. Con el fin de explorar las razones de esta apatía, pretendemos dar cuenta de las tareas que la educación puede ser llamada a desempeñar para mejorar la democracia. En este sentido, a través del uso de material de investigación empírico recogido en tres escuelas secundarias de Lisboa, principalmente a través de entrevistas semiestruturadas y observación de actividades promovidas por los propios alumnos, los resultados sugieren una pluralidad de compromisos y relaciones con la política, que corresponden a una diversidad de tareas que la escuela puede desempeñar en la formación política de los jóvenes. Así, paralelamente a la socialización política clásica, encontramos el compromiso por individuación, caracterizado esencialmente por la participación en la vida de la escuela y por la voluntad de experimentación, y el compromiso por la subjetivación, como una problematización de la política centrada en su propia auto-mejora. Estos compromisos, que pueden ser combinados, representan tanto diferentes formas de ser como marcos morales de evaluación y acción. Representan un ámbito más amplio de la política como una experiencia de relación con el mundo.

PALABRAS CLAVE: Política. Educación. Juventud. Escuela secundaria. Gran Lisboa. Procesos de participación.

\section{INTRODUÇÃO}

Têm-se recentemente multiplicado os estudos sobre a apatia política dos jovens portugueses com o objetivo de identificar as variáveis suscetíveis de predizer o seu comportamento político. $\mathrm{Na}$ base da maioria destes estudos, quer de natureza quantitativa (Magalhães, 2008; Lima e Artiles, 2014; Lobo et al., 2015), quer de natureza qualitativa (Varela, 2009), encontra-se, porém, uma perspetiva restritiva do conceito de política, seja na esteira tradicional da sociologia da política (Aguiar, 2007), ou na da sociologia política, onde a relação com a política, no rastro do gesto inaugural de Sartori (1969), é representada como uma relação de mercado, pela qual esta tende a equivaler-se à oferta de um bem, ao passo que o comportamento político dos jovens é equiparado ao comportamento de um mero consumidor.

A distanciação face à política e a fraca participação nas atividades em comum estendese, não surpreendentemente, à própria vida na escola, porventura iniciando-se aí mesmo

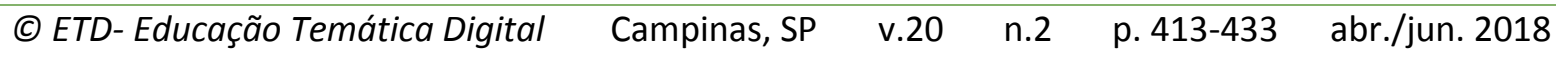


(Lopes, 1997; Lima, 1998; Resende, 2010). O problema da participação na vida societária coloca-se assim tanto ao nível macro como micro, avolumando-se as preocupações quanto à qualidade da democracia (Lisi et al., 2013). De resto, um inquérito feito para a União Europeia sobre a participação dos jovens na vida democrática, em 2013, revela um decréscimo na participação eleitoral dos jovens portugueses (EC, 2013, p. 12) e adianta dados inquietantes sobre a relação entre os jovens e a política. Assim, apenas 19\% dos jovens declara considerar vir a ser candidato a uma eleição política face a $79 \%$ que rejeitam a ideia. A cifra é exatamente a média europeia. Todavia, são os mais jovens, com idade entre 15-19 anos, e os menos escolarizados, os mais propensos a dizer que considerariam essa hipótese.

Ressalta ainda do inquérito realizado de que aqueles que já participaram em organizações juvenis são os que demonstram maior interesse pela política (EC, 2013, p. 17). Por conseguinte, os hábitos participativos em associações juvenis, mormente nas estruturas associativas das escolas, poderão favorecer um maior interesse pela política. No fundo, a escola, afinal de contas a sua segunda casa, constitui-se como uma sociedade política em miniatura (Dewey, 2007; Durkheim, 2012): aquela que lhes é mais próxima e afeta mais diretamente as suas vidas.

Estes estudos, embora nem sempre sejam coincidentes em alguns dos seus resultados, uma vez que as amostras diferem, ${ }^{2}$ mostram que os jovens portugueses parecem não divergir substancialmente dos seus congéneres europeus, bem como do conjunto da população portuguesa, nos seus baixos índices de participação e pouco interesse, quando não mesmo uma rejeição, pela política. Mas mostram igualmente a centralidade que a problemática da socialização política tem vindo a assumir na literatura sobre a relação dos jovens com a política (Braud, 2009). ${ }^{3}$ Sob este ângulo, mais do que os fatores preditivos,

\footnotetext{
${ }^{2}$ Num estudo de 2008 encomendado pela Presidência da República, Magalhães e Moral (2008, p. 18), afirmam que, diferentemente de quase todos os outros países europeus, "existe em Portugal uma "ausência de diferenças entre os jovens adultos e o resto dos ativos". Por conseguinte, segundo estes autores, "no caso português, a posição no ciclo de vida não deverá ser a única explicação para uma relação entre a idade e o interesse pela política" (Magalhães e Moral, 2008, p. 18). Num segundo estudo, de 2015, também patrocinado pela mesma instituição, Lobo et al. sugerem a existência de "uma curvilinearidade entre participação cívica e idade" (Lobo et al., 2015, p. 52). Uma curvilinearidade que também se estende aos efeitos da escolaridade dos pais dos jovens: "são aqueles com pais sem nenhuma ou com pouca escolarização, e os que têm pais mais escolarizados com percentagens acima da média de identificação partidária" (Lobo et al., 2015, p. 63). Ou seja, por um lado, isto tende a reforçar a ideia de que a integração dos jovens, realizando-se naturalmente passo a passo, mas acompanhada pelo correspondente pacote de responsabilidades que a passagem do tempo acarreta, favorece uma maior participação política. Por outro lado, uma socialização política associada a uma identificação partidária traduz-se em maiores probabilidades de participação política.

${ }^{3}$ Varela, na sua tese de mestrado sobre jovens e a política, procedendo a uma análise qualitativa, observou que "a socialização política favorece efetivamente o interesse pela política e a participação política, embora não seja claro qualquer tipo de associação positiva com a identificação partidária" (Varela, 2009: 196).
}

(C) ETD-Educação Temática Digital Campinas, SP $\quad$ v.20 $\quad$ n.2 $\quad$ p. $413-433 \quad$ abr./jun. 2018 
ganham realce o aprofundamento dos processos de engajamento político dos jovens, as diferentes instâncias de socialização, o seu entendimento do que é a política, bem como o modo como os jovens se relacionam consigo mesmos enquanto sujeitos políticos.

Visando conhecer as perspetivas dos jovens, torna-se relevante para este efeito, considerar uma abordagem que possa acomodar e fazer jus à experiência dos jovens, bem como às tonalidades dos seus engajamentos (Thévenot, 2006). Uma aborgagem suficientemente abrangente que, de acordo com uma definição alargada do fenómeno da socialização política, permita reconstituir quer o conceito de política, quer o conceito de socialização. Uma definição ampla de política, no sentido arendtiano do termo (Arendt, 2005), como exprimindo uma relação com o mundo, a qual inclui a relação com os outros, mas também a relação consigo próprio. No que concerne ao conceito de socialização, este tem sido recentemente colocado à prova, tanto na literatura sobre a socialização na infância (Garnier, 2010; Castro, 2016) como na da socialização política da juventude (Caetano, 2016; Castro e Grisolia, 2016).

Concorrendo para a reformulação concetual deste domínio de estudo destacam-se os novos e decisivos contributos dos últimos trabalhos de Foucault, nomeadamente Le Gouvernement de Soi et des autres (Foucault, 2008) e L'origine de l'herméneutique de soi (2013), perspetivados no âmbito de uma "reelaboração da teoria do sujeito" (Fujita, 2015, p. 14) e visando a análise das condições da sua produção. A sua especial importância diz respeito ao reequacionamento da política como conjunto de técnicas de governamentalidade e ao reexaminamento da socialização enquanto subjetivação das práticas.

Com efeito, ao problematizar a política enquanto "conduta da conduta», nestas investigações, Foucault reconhece a centralidade que as funções mediadoras dos conceitos de poder e de verdade podem efetivamente desempenhar nos estilos de compromisso que o sujeito estabelece com o discurso que é veiculado, mas também com os outros e consigo próprio. Deste modo, a socialização política, enquanto conjunto de processos identitários, para além de ter de comprometer os jovens com o mundo que os rodeia, horizonte alargado de possibilidades de atuação, e com a escola, o meio imediato onde estão inseridos, compreende ainda o conjunto de processos de coordenação moral consigo próprio.

O propósito deste artigo, a partir do tríptico democracia, jovens e educação, e considerando a política como algo que pré-existe aos jovens e na qual estão imersos, visa dois objetivos concatenados. O primeiro prende-se com a articulação entre os três eixos analíticos anteriormente identificados - o mundo, a escola e o si próprio, projetados enquanto horizontes significativos de ação - e as perspetivas de engajamento dos jovens. Por outras palavras, pretende-se mostrar que estes horizontes da socialização política se associam

$\begin{array}{llllll}\text { (c) ETD-Educação Temática Digital } & \text { Campinas, SP } & \text { v.20 } & \text { n.2 } & \text { p. 413-433 } & \text { abr./jun. } 2018\end{array}$


estreitamente com as diferentes perspetivas de engajamento. Em um segundo momento, procura-se explorar e esclarecer as tarefas que a educação pode ser chamada a desempenhar na melhoria da democracia com base na pluralidade destes mesmos envolvimentos.

As perspetivas de engajamento emergem de uma investigação qualitativa sobre os processos de socialização política dos jovens estudantes efetuada em três escolas secundárias socialmente contrastantes da Grande Lisboa, com o intuito de conhecer o modo como os jovens se mobilizam para fazer o comum nas escolas. A metodologia assenta em duas técnicas de recolha empírica: as entrevistas aprofundadas, realizadas a 28 jovens estudantes do ensino médio ao longo dos anos 2010-2011; e a observação direta de uma atividade realizada por jovens para jovens, sob o modo de projeto e intitulada "Política somos nós», a qual decorreu no âmbito de uma disciplina do 12 을 a de escolaridade (final do ensino médio) numa das escolas selecionadas.

O artigo encontra-se dividido em três secções: logo depois da metodologia, procedese à ilustração empírica das modalidades de engajamento dos estudantes, segmentadas em quatro subsecções. As modalidades, que configuram perspetivas, mostram-nos outras tantas formas de conceitualizar a política, reconhecendo-se nelas um conciso repertório das tarefas de uma educação para a democracia, objeto da terceira secção do artigo.

\section{MÉTODO}

O desenho da investigação assenta, em grande medida, na técnica da entrevista semidiretiva, uma vez que esta permite o centramento no percurso do jovem e nos seus hábitos e tendências de engajamento. No fundo, nas suas regras de experiência. A seleção das escolas obedeceu a uma diversidade de características (classe social dos pais dos alunos, trajetórias da escola, localização centro-periferia, projeto educativo), com o objetivo de captar uma ampla pluralidade contextual nos percursos dos jovens estudantes, mais do que propriamente encontrar fatores explicativos como, por exemplo, a classe social. Assim, dos 28 entrevistados, 14 pertencem ao sexo masculino e 12 frequentavam o 10 ano (entrada no ensino médio). A ligeira dominância de alunos do 12 ano deve-se ao fato de se ter dado preferência a um outro critério de seleção: o de pertencer ou desejo de pertencer à Associação de Estudantes da Escola (AE). O processo de amostragem foi o de bola de neve, com o auxílio de informantes privilegiados: professores e alunos. As entrevistas realizaramse ao longo do ano letivo 2010-11, tendo para o efeito sido construído um guião com questões e tópicos afins assente nos diferentes contextos de experiência dos alunos, nomeadamente o seu quotidiano, a participação em atividades, as regras de conduta e de convivência ou o seu relacionamento com as instituições e com a política.

$\begin{array}{llllll}\text { (c) ETD-Educação Temática Digital } & \text { Campinas, SP } & \text { v.20 } & \text { n.2 } & \text { p. } 413-433 & \text { abr./jun. } 2018\end{array}$ 
Aos estudantes inquiridos foi-lhes explicado claramente os objetivos da entrevista numa nota introdutória às mesmas, bem como explicitada a garantia de anonimato e confidencialidade quanto à sua identidade. Foi obtido o seu consentimento para a sua gravação em formato digital e ulterior transcrição. A análise das entrevistas procura explorar o engajamento dos atores nas situações. Em lugar de uma análise dos fins e dos meios (Bardin, 2003, p. 123-124), privilegia-se uma análise perspetivada nas modalidades e engajamentos dos atores nas situações. Para dar conta de que existem diferentes trajetórias de engajamento, procura-se, por um lado, respeitar cada entrevista como um caso de estudo formando um todo original e singular e, por outro lado, respeitar uma certa comparabilidade dos casos. Consequentemente, a análise combina alguns procedimentos de análise temática com outros provenientes da análise de enunciação (Bardin, 2003, p. 172), a mais adequada para referenciar as motivações, atitudes e representações dos atores.

Para além das entrevistas acompanhou-se ainda uma atividade de projeto desenvolvida por jovens para jovens, em contexto escolar e no âmbito de uma disciplina do 12 ano, subordinada ao tema "a falta de interesse dos jovens na política do nosso país". Apresenta-se seguidamente os resultados empíricos da pesquisa qualitativa efetuada, procurando mostrar, a partir de casos sugestivamente ilustrativos, o que move os jovens estudantes entrevistados na pluralidade dos seus engajamentos.

\section{OS ENGAJAMENTOS POLÍTICOS DOS JOVENS ESTUDANTES}

A partir da análise do material recolhido, apresentam-se nesta seç̧ão quatro perspetivas diferentes da política, as quais mostram uma pluralidade de engajamentos políticos possíveis em situação: um projeto realizado por jovens com a presença de figuras políticas; as reivindicações da Associação de Estudantes junto da Direção da Escola propondo um novo arranjo institucional; o gosto da participação em atividades comuns; o investimento em si próprio cujos efeitos incluem a formação de uma pessoa mais esclarecida. Começaremos por abordar a perspetiva clássica da política presente no projeto realizado pelos jovens para jovens.

\section{A perspetiva clássica da política: conhecer para melhorar o mundo}

Despontar o interesse pela política, o qual pode ser alimentado e nutrido no meio familiar ou em outros círculos sociais mais específicos, é uma das missões da escola. Efetivamente, o alongamento da escolaridade obrigatória para os doze anos, o qual se acompanha de uma "alunização da juventude" (Vieira et al., 2015), alarga consideravelmente a influência da socialização em meio escolar, seja pela via institucional ou pela via de uma socialização pelos pares.

$\begin{array}{llllll}\text { (C) ETD- Educação Temática Digital } & \text { Campinas, SP } & \text { v.20 } & \text { n.2 } & \text { p. 413-433 } & \text { abr./jun. } 2018\end{array}$ 
De facto, a dimensão política instrutória da escola portuguesa tem sido reforçada nos últimos anos com a introdução de novas disciplinas e áreas disciplinares no seu currículo oficial. Primeiramente, com a implementação da disciplina de educação para a cidadania, em 2001, no 2o e 3o ciclo do ensino básico (dos 10 aos 14 anos) e, a partir de 2004, com a área disciplinar transversal de Educação para a Cidadania no ensino secundário (dos 15 aos 17 anos). Não obstante, continuam a ser as disciplinas clássicas os instrumentos escolares privilegiados para a transmissão de conteúdos relacionados com a política. A disciplina de História desempenha aqui um papel crítico na paixão pelos fenómenos políticos. A 'paixão' enquanto qualidade sine qua non do político, de que nos fala Weber (1967) em A política como vocação.

Houve ocasião de comprovar isto mesmo nas entrevistas efetuadas em três escolas secundárias da Grande Lisboa. Quase todos os alunos 'apaixonados' pelo conhecimento político entrevistados, e que constituem uma minoria na amostra, confessaram-se atraídos, não pelos problemas políticos concretos da atualidade nacional, mas sobretudo por via discursivo-afetiva de uma história narrada a partir de grandes feitos heroicos do passado. Por exemplo: "Tivemos uma professora espetacular, explicou de uma forma simples, objetiva"; "apoiou-nos imenso" (Diretora de turma do 10, 11ㅇ e 12ㅇano); "Era dado de uma forma mais romântica; como se estivéssemos a ler um livro ou a ver um filme"; de "forma mais entusiasmante", com "dinamismo". Estes relatos comprovam as conclusões de Pais (1999) quanto à eficácia em Portugal de uma socialização política baseada na transmissão oral de um imaginário impressivo.

A centelha, o ímpeto de "descobrir o mundo", pode-se acender ainda mais cedo, no 9o ano de escolaridade, como revelam outros três jovens, dos quais falaremos adiante. Fascinados por biografias históricas de figuras que transformaram o mundo, homens que conseguiram impor ideias, homens com força, confiam-nos: "Passávamos as horas de almoço e do intervalo a discutir política". O seu interesse específico pela política foi alimentado quase inteiramente na escola: "aqui [escola] posso falar das coisas em geral", "em casa é sobre as coisas (decisões) que nos afetam pessoalmente". A escola é o espaço onde "aprende-se mais com as diferenças uns dos outros" e "vamos conhecendo o que falta conhecer".

Um outro jovem do 12ㅇ ano refere a disciplina de Economia: "Quando a gente tinha aula de Economia, por exemplo, a gente falava sobre isso, falávamos sobre a Assembleia da República, o Estado, essas coisas". A Economia é "um discurso que eu... Há outro discurso..., mas é um discurso de que eu gosto muito..., é uma disciplina que eu tive... que eu gostava muito, por acaso, por causa de debates". O que o move é sobretudo a curiosidade de ficar "a

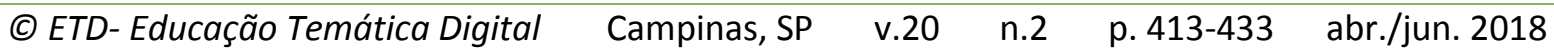


saber sobre... sobre o que está a acontecer no mundo, sobre a economia, sobre tudo, sobre tudo no mundo".

Conceber a relação dos jovens com a política, ensaiada por jovens para jovens, foi aquilo que fizeram os três jovens acompanhados ao longo do ano letivo 2009/2010, quando os mesmos implementavam um projeto para atrair os seus colegas para a política, no âmbito da disciplina não curricular do $12^{\circ}$ ano, Área de Projeto, entretanto extinta. O projeto tinha como tema a "falta de interesse dos jovens na política do nosso país", que, acreditavam, ser essencial à democracia. Querendo fazer algo que pudesse causar impacto e fazer a diferença na escola, programaram uma intervenção assente em várias atividades: o lançamento de um questionário exploratório junto de uma amostra de colegas do ensino secundário, para medir o seu conhecimento sobre política e o seu grau de interesse pela mesma; a criação de um blogue sobre a temática, abrindo um espaço de partilha e de opinião sobre temas políticos; a organização na escola de um ciclo de palestras com personalidades cimeiras da política portuguesa, abrangendo todo o espectro político-partidário, e convidando-as a emitir um discurso de encorajamento dos jovens pela política; a mediatização da iniciativa junto de órgãos de comunicação social a nível nacional; e, por fim, a organização de uma visita à Assembleia da República com algumas turmas da escola para assistirem aos trabalhos plenários finais da iniciativa do "Parlamento dos Jovens», onde os jovens de todas as escolas do país, após sucessivas eliminatórias locais e regionais assimiladas a processos eleitorais, se reúnem para mimetizar as tarefas de um deputado nacional: debater e aprovar projetos de recomendação.

A centralidade da intervenção radicava no ciclo de palestras e, por isto mesmo, os três jovens conseguiram trazer à escola três líderes partidários e um ex-primeiro-ministro, em 4 sessões agendadas ao longo de pouco mais de dois meses. O feito trouxe-lhes notoriedade e simultaneamente uma pressão acrescida diante dos acontecimentos, bem como alguns obstáculos e polémicas que tiveram de ultrapassar. Por exemplo, ter de garantir que os organizadores não estavam comprometidos com nenhum partido; que não procuravam favorecer nenhum partido ou figura política em particular; que tinham convidado pessoas dos partidos mais representativos; e, por fim, de que não haveria por parte dos conferencistas um aproveitamento político-partidário do evento. Assim, tiveram de tornar públicos os seus desideratos, de modo a poder superar o confinamento da querela encetada por aqueles para quem a neutralidade política da escola é um dever, numa interpretação, porventura demasiado severa, dos escrúpulos weberianos acerca da missão da escola na sua tarefa de socialização política (Corcuff, 2011).

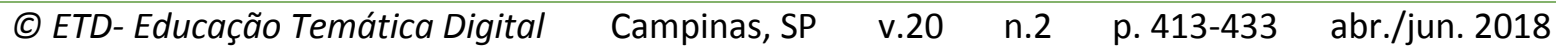


Os desígnios de socialização política veiculados nestas ações de sensibilização podem ser facilmente reconhecidos no testemunho de um dos palestrantes, quando o mesmo partilhou a sua ideia sobre o que deve ser a política: "trabalhar para melhorar a vida dos outros"; "A política é servir a comunidade"; "Não há cargos mais bonitos do que os do poder local, trabalhar perto das pessoas e poder mudar a vida delas"; "A política vale a pena. É fundamental ser sério". Adotando um estilo simultaneamente senatorial e confessional, este político deixou alguns conselhos à plateia, fundamentais no seu entender para se querer abraçar a atividade política.

O primeiro: "Construirmos a nossa base antes de irmos para a política", isto é, devemos viver para a política e não viver da política. Segundo, ter notas de "Bom», no mínimo". Em terceiro lugar, a importância da autodisciplina para se ser bem-sucedido: "Trabalho muito. Tenho muito mau feitio para trabalhar". Na esteira de Max Weber (1967), acoplada à disciplina vem o sentido de responsabilidade - "Temos de assumir responsabilidades pelo que fazemos" -, bem como o respeito pelas diferentes grandezas dos seres (Boltanski e Thévenot, 1991): "Isso é correto [referindo-se às formas de tratamento social] (...) é uma questão de regras, de respeito: a vida não pode funcionar sem regras". Ao estilo eloquente dos grandes clássicos literato-humanísticos, o orador abordou ainda um conjunto de tópicos que versavam a dignidade, a bondade ou a humildade.

Este exemplo mostra como, pela via da escolarização, a significância do político é transmitida pela palavra de geração para geração, com o propósito duplo de inserir os jovens numa ordem histórica determinada, cativando-os, instilando-lhes a paixão pelo conhecimento do mundo, e, simultaneamente, procurando elevá-los a uma grandeza moral representativa do interesse comum, de comprometimento de serviço público, objetivando deste modo esta mesma paixão. Estamos assim na presença de uma política dos grandes ideais, uma política embasada na autoridade, a qual comporta um "valor mais alto», nas palavras de Paul Ricœur (2004, p. 309), um "«valoir-plus», da qual não se pode passar sem evocar uma dimensão de altura".

\section{A perspetiva normalizadora da política: trabalhar para melhorar a escola}

Numa entrevista, o presidente da Associação de Estudantes (AE) de uma das escolas, sendo também dirigente de uma juventude político-partidária desabafa: "eu pessoalmente acho que poderiam garantir mais objetividade e maior homogeneidade e igualdade dentro do sistema de ensino". Reconhecendo que existem correções a fazer no sistema educativo, afirma-se, todavia, favorável à manutenção dos exames nacionais (ao contrário de muitos dos colegas do ensino secundário que se deixam politizar facilmente), pois "é muitas vezes a única

$\begin{array}{llllll}\text { (c) ETD-Educação Temática Digital } & \text { Campinas, SP } & \text { v.20 } & \text { n.2 } & \text { p. } 413-433 & \text { abr./jun. } 2018\end{array}$ 
garantia que nós temos que existe maior equidade, relativamente àquele que teve um professor que se interessa muito... Que se interessa ou que dá melhores notas".

Numa posição que lhe concede legitimidade na defesa dos interesses dos alunos, este dirigente, aquando da revisão do Regulamento Interno da escola, tenta bater-se por critérios gerais e objetivos "que permitissem aos professores salvaguardar a sua posição e permitissem aos alunos, caso se vissem numa situação de injustiça, poderem reivindicar os seus direitos com base em alguma coisa de concreto". Enquadra-se neste âmbito o direito de assistência às aulas de um aluno que tem uma disciplina por fazer do ano anterior, mas que não se encontra matriculado na mesma e sim na disciplina mais avançada do ano que frequenta. $A$ AE pretendia a formalização do direito de assistência dos alunos, com a "passagem para a escrita daquilo que já era prática corrente na escola, portanto, transferência para o papel, ou seja, passaria a institucionalização". Deparou-se com o argumento de que "é tudo visto caso a caso, só caso a caso é que isso é definido e (...) O único elemento, diria eu, que será mais objetivo e que mesmo assim não está lá escrito, é... por exemplo, se tivermos uma turma lotada, provavelmente será mais difícil que o aluno seja inserido".

Para o dirigente esta resposta é claramente insatisfatória, pois, como refere: "nós não temos nenhuma segurança. Não é desconfiar das instituições, nem da boa-fé da direção, nem dos professores, mas nós não temos qualquer tipo de segurança de poder fazer valer o direito à assistência das aulas". Não concordando com a resistência dos professores em consagrar o direito de assistência dos alunos, pois "mesmo que exista boa-fé e que exista bom senso da outra parte, o fato de isto ser construído num modelo perfeitamente arbitrário leva a que nós, a partir desse momento, já desconfiemos daquilo que possa vir do outro lado"; ele continua a insistir na necessidade de "normalização" da situação do aluno assistente.

Neste particular, a regularização e a uniformização das decisões contribuiriam decerto para potenciar atitudes menos revoltadas ou atitudes resignadas e impotentes dos alunos. A normalização das situações recriaria certamente um ambiente mais favorável à individuação dos alunos, ao fixar-lhes as condições de possibilidade da sua atuação, assentes na sua capacidade de decisão e não nos sentimentos paternalistas do professor. Permitiria aos estudantes testarem a fiabilidade das estruturas objetivas do sistema e, acima de tudo, não desconfiarem da bondade dos professores. Estas considerações do estudante, em nosso entender, ilustram muito claramente o método de observação e de reflexão defendidos pelo filósofo John Dewey. Na verdade, para este pensador estado-unidense, a verdadeira educação, nascendo da interação entre as pessoas e as instituições, encontra-se na inovação dos arranjos institucionais, pelo que "as operações e resultados do inquérito natural ganham

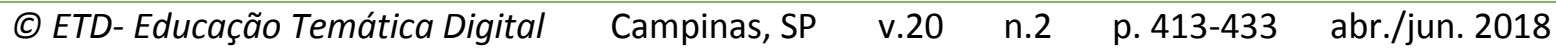


em prestígio e poder a expensas dos princípios ditados pela alta autoridade" (Dewey, 1920, p. 47-48).

\section{A política pela experimentação}

Quando se perguntou a um membro de uma Associação de Estudantes se se interessava pela política, a resposta foi: "É assim, não. Política não, mas ...algumas coisas sim, que eu gostava de mudar, como é claro". Insistindo, referiu: "Cá na escola, por exemplo, essa...mesmo que não me afete a mim, acho que para algumas pessoas faz sentido... Há coisas que se calhar não fazem sentido, não sei... Que podem ser melhoradas..., mas não...". Ao indagarmos se as coisas a melhorar no País não a fariam também interessar-se pela política, retorquiu: "Acho que não, acho que é muito difícil alguém conseguir mudar mesmo as coisas. Acho que é impossível, principalmente no país em que nós estamos". À nossa perplexidade, acrescentou: "acho que as pessoas, em geral, a população toda, não se interessa por trabalhar, só querem é vantagens e isso assim... Sinto-me um bocado à parte... Não penso muito nisso, se calhar, devia pensar mais, mas não...".

Todavia, esta mesma jovem não deixa de salientar "que é importante nós fazermos alguma coisa pela escola e pelos nossos colegas e de alguma forma mudar as coisas que achamos que não estão bem". Por isso mesmo deplora a apatia dos colegas aquando das últimas eleições para a Associação de Estudantes: "houve aqui gente que nem sequer se preocupou em votar, nós tínhamos que estar a pedir: 'ai não querem vir votar', tínhamos que incentivar um bocado". Aborrecida com o fato de que os colegas "nem sequer dão valor nenhum... Eu acho que pensam um bocado que as coisas aparecem do nada, não sei (...)", associa o interesse pelas coisas às atividades que se exercem na escola e que dizem respeito a todos, enquanto comunidade de jovens estudantes. Por isso refere que o interesse pela escola, isso "depende de aluno para aluno, mas ...os que se interessam em aprender e que têm perspetivas de ir para a universidade e entrar com boas notas, eventualmente isso tudo, interessam-se pela escola também".

O fato de não ser movida por questões ideológicas ou interesses corporativos ou individuais, no sentido de adquirir 'vantagens', significa que não se sente ainda um membro diretamente afetado pelas decisões políticas nacionais, mas tal não impede de se se sentir membro da sociedade política da escola que frequenta e de assim "tentar melhorar algumas condições cá na escola". Gostando de ajudar, de participar, afirma que "não têm que ser as outras a pensar (...) que as outras pessoas têm que vir falar connosco. Nós, se calhar, é que temos que fazer um bocado a nossa parte". Esta estudante, para além de ser membro associativo, frequenta também o ateliê de cerâmica na escola, onde contacta com alunos invisuais, e gostaria ainda de fazer parte do teatro da escola. Quando nos revelámos

$\begin{array}{llllll}\text { (c) ETD-Educação Temática Digital } & \text { Campinas, SP } & \text { v.20 } & \text { n.2 } & \text { p. 413-433 } & \text { abr./jun. } 2018\end{array}$


admirados com tanta atividade, afirmou: "normalmente as pessoas centram-se só numa coisa, eu, por acaso, gosto de ter sempre (...) gosto de experimentar tudo".

\section{A perspetiva problematizadora da política e o aperfeiçoamento de si próprio}

Um jovem no início do ensino secundário (10 ano) referiu, logo no início da entrevista, que não queria "ter um papel muito ativo na política". Acrescentando: "mas são coisas que vamos aprendendo, se calhar, daqui a uns anos, eu vou mudar de opinião e vou ser uma pessoa completamente diferente, mas neste momento é o que eu queria fazer". Para ele a sociedade em que vive é caraterizada pelo consumismo e o conformismo, logo, é uma sociedade, nas suas palavras, 'hipócrita'. Quando questionado sobre as formas de mudar a sociedade, o mesmo reconhece: "Qual é o jovem que não quer mudar o mundo, que não quer ser diferente? Acho que todos os jovens querem ser importantes, querem ter um foco". Mas em vez de procurar mudar a sociedade, este jovem preconiza "a liberdade para nós mesmos. Podemos estar numa prisão, estar presos e sermos livres". Nisto, "não quer dizer que não haja sociedade, porque a sociedade é um conjunto de pessoas, não é? Devemos melhorar, sermos melhores pessoas"; "mas não como sociedade, como indivíduos".

O mesmo jovem, popular na escola, até já pertenceu a uma lista concorrente às eleições para a $A E$, pois "uma associação de estudantes procura sempre os alunos que são mais conhecidos, que têm mais influência, se assim se pode dizer, para ganhar votos". Ajudou a lista a ganhar votos, mas não quis envolver-se mais na atividade associativa: "lá está, porque descobri a minha outra... Descobri-me a mim mesmo. E acho que isso para mim foi um grande passo. Provavelmente, se tivesse amigos na Associação, se calhar, até os podia ajudar, mas...não se calhar assim de uma forma muito ativa, e era mais divertimento, nunca entrei nas questões mais políticas". Envolvido na campanha eleitoral, este jovem descobriu-se e foi esta experiência que se lhe revelou significativa.

Um outro jovem no final do ensino secundário (12ㅇ ano) exprime as suas reservas morais relativamente ao seu engajamento na atividade política e que se estendem a todas as atividades relacionadas com o poder. As suas conceções éticas não se coadunam com a interpretação que faz da política:

Sim, acho que é muito difícil e acho que é muito difícil um político que seja honesto
fazer alguma coisa sem ter de conceder favores, ou sem... Portanto, acho que a
honestidade é uma forma muito difícil de obter resultados (...) Eu não me quero
meter nisso. Eu nem quero meter a hipótese nesse aspeto. Porque eu tenho a plena
noção de que o poder muda as pessoas, completamente, então não quero sequer
chegar a uma posição de poder. Eu não 'tou a falar em termos políticos, também
profissionais. Claro que se fizer bem o meu trabalho, nesse aspeto, claro que vou
aceitar uma... Se for uma empresa, é claro que vou aceitar a promoção, ou... Mas,

(C) ETD- Educação Temática Digital Campinas, SP $\quad$ v.20 $\quad$ n.2 $\quad$ p. 413-433 abr./jun. 2018 
onde possa, de fato, mudar a vida das pessoas; e eu não sei se alguma vez vou aceitar um cargo com uma grande importância a nível político, se alguma vez vou concorrer, ou se... Acho que não, a não ser que sinta que possa, de fato, mudar alguma coisa e que não tenha... E que já não tenha receio desse poder, porque eu ainda estou numa fase de formação da minha pessoa e ainda não sei se a minha cabeça vai mudar ou se vai... Ou se vou ficar na mesma, por isso, ainda não sei, mas, para já, rejeito essa hipótese de entrar no mundo da política.

Uma certa ideia de honestidade e não corrupção de si mantém este jovem resguardado da política. Refere que não é uma pessoa naturalmente reservada e tímida, mas que, ao invés, pratica uma constante vigilância sobre si próprio, intensificando por assim dizer o seu trabalho na subjetivação:

Não é que eu seja, naturalmente mais discreto, mas tento esforçar-me muito para ser mais discreto. Não é bem assim... É mais... Eu consigo ser uma pessoa arrogante, por vezes, e consigo ser uma pessoa, por vezes, que gosta de falar e gosta de se ouvir, mas tento muito ser humilde e reconheci isso (...)

O seu trabalho de subjetivação faz articular conviç̧ões com práticas visando a modificação de si. A vigilância que ele exerce sobre os seus pensamentos e as suas ações previnem-no de exercer naturalmente o poder, sem antes o problematizar a respeito dos efeitos que poderão ocorrer em si próprio. A ambição, a arrogância ou a ignorância têm de ser imediatamente detetadas e implacavelmente extirpadas para dar lugar a manifestações que traduzam os ideais mais "nobres» de modéstia, de humildade ou de inteligência. O si é o foco e o cerne das relações do sujeito com o mundo. E é neste sentido que poderemos falar do "cuidado de si", que significa uma "atitude diferente consigo, com os outros e com o mundo" (Candiotto, 2008, p. 91).

\section{AS TAREFAS DA EDUCAÇÃO À LUZ DOS ENGAJAMENTOS POLÍTICOS DOS JOVENS}

Com base nas perspetivas de engajamento político acabadas de evidenciar, pode-se, para os casos estudados, delinear um esboço da relação multidimensional dos jovens com a política. O Quadro 1 apresenta de uma forma sintética esta mesma relação, fornecendo uma matriz que combina as perspetivas com os eixos analíticos, bem como as trajetórias de engajamento. Estas, referentes aos engajamentos por socialização, individuação e subjetivação, serão objeto de explicitação mais adiante, aquando da explicitação da matriz.

Da leitura do Quadro I denota-se que as quatro perspetivas identificadas percorrem os três eixos analíticos considerados, permitindo constatar a modulação que os engajamentos políticos adquirem ao longo dos diversos eixos. Assim, se na perspetiva clássica, no que diz respeito a melhorar o mundo se privilegia a argumentação e o respeito pelas convenções, na

$\begin{array}{llllll}\text { (c) ETD-Educação Temática Digital } & \text { Campinas, SP } & \text { v.20 } & \text { n.2 } & \text { p. } 413-433 & \text { abr./jun. } 2018\end{array}$


perspetiva normalizadora, ao invés, destaca-se o desígnio de contribuir ativamente para a criação de um acordo de equidade através de arranjos locais, ao passo que, na perspetiva da experimentação, o desejo de contribuir ativamente para melhorar o mundo é colocado em suspensão, em proveito de uma vontade de participação na melhoria da escola, tarefa imediatamente ao alcance dos esforços políticos de transformação dos jovens. Na perspetiva problematizadora, regista-se, porém, um certo retraimento face à ideia de colaborar decididamente na transformação política do mundo.

QUADRO 1 - A multidimensionalidade dos engajamentos políticos

\begin{tabular}{|c|c|c|c|c|c|}
\hline Perspetiva & Clássica & & Normalizadora & Experimentação & Problematizadora \\
\hline & Socializ & & Individuação & Subjetivação & \\
\hline $\begin{array}{r}\text { Melhoraro } \\
\text { mundo }\end{array}$ & 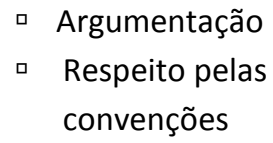 & $\begin{array}{l}\square \\
\square\end{array}$ & $\begin{array}{l}\text { Arranjos gerais } \\
\text { Equidade } \\
\text { (fairness) }\end{array}$ & - Fora do alcance & $\begin{array}{ll}\square & \text { Resistência } \\
\square & \text { Retraimento }\end{array}$ \\
\hline $\begin{array}{r}\text { Melhorar a } \\
\text { escola }\end{array}$ & $\begin{array}{ll}- & \text { Estudar } \\
- & \text { Cumprir regras }\end{array}$ & $\begin{array}{l}\square \\
\square\end{array}$ & $\begin{array}{l}\text { Arranjos locais } \\
\text { Equidade } \\
\text { (fairness) }\end{array}$ & $\begin{array}{ll}\text { - Experimentação } \\
\text { - Participação }\end{array}$ & - Indiferença \\
\hline $\begin{array}{r}\text { Melhorarosi } \\
\text { próprio }\end{array}$ & $\begin{array}{ll}\square & \text { Bondade } \\
\square & \text { Humildade }\end{array}$ & $\begin{array}{l}\square \\
\square\end{array}$ & $\begin{array}{l}\text { Objetividade } \\
\text { Prudência }\end{array}$ & $\begin{array}{ll}\text { - } & \text { Atividade } \\
\text { - } & \text { Curiosidade } \\
\text { - } & \text { Criatividade }\end{array}$ & $\begin{array}{ll}\square & \text { Coragem } \\
\square & \text { Honestidade } \\
\square & \text { Humildade }\end{array}$ \\
\hline
\end{tabular}

Relativamente ao eixo de melhorar o si próprio, observa-se igualmente uma variação nas qualidades mais valorizadas, desde a bondade (fazer o que é bom e o que é correto) na perspetiva clássica, ou a objetividade na perspetiva normalizadora, à atividade e à curiosidade na perspetiva da experimentação, ou ainda à coragem e honestidade na perspetiva problematizadora. Estas cambiantes não devem ser consideradas como categóricas, mas como tonalidades de engajamento que exprimem diferentes pontos de vista.

A perspetiva clássica, não obstante, poder constituir-se como uma antecâmara preciosa de entrada no universo simbólico da política, apresenta alguns resultados não esperados para o caso português, mormente o de contribuir para a preservação e a reprodução simbólica dos arranjos institucionais vigentes, seja pelo privilégio que a memória narrativa do passado adquire, com todo o seu peso e drama no enredo, seja pela ênfase concedida à dimensão ética do respeito pelas convenções. Ela corresponde a uma socialização 
de tipo clássico, na esteira de Durkheim. ${ }^{4}$ Todavia, o excessivo peso da escolarização na formação argumentativa e crítica dos jovens na sua preparação para o mundo, ${ }^{5}$ pode constituir um obstáculo à participação na vida escolar, sobretudo se a escola não apresenta o dinamismo e as oportunidades concretas e práticas para a sua fomentação.

A perspetiva normalizadora, por seu turno, constitui-se como uma perspetiva não subjetivista nem conformista da política, informada por um espírito mais concentrado na fabricação dos arranjos de equidade, do que propriamente com as questões relacionadas com a hierarquia e a igualdade, focos privilegiados da perspetiva clássica. ${ }^{6} \mathrm{Na}$ perspetiva normalizadora, as questões da equidade podem colocar-se quer ao nível local da escola, quer ao nível geral. Ela relembra-nos a proposta do liberalismo «radical» de John Dewey, para quem o problema da democracia prende-se com uma melhoria na organização social, pela qual "as capacidades dos indivíduos seriam não somente libertadas dos constrangimentos mecânicos externos, mas além disso alimentadas, sustentadas, guiadas" (Dewey, 2007, p. 99). Para a sua consecução seria necessária não apenas uma instrução geral, mas uma verdadeira educação pelo método experimental (a inteligência deweyana) a ter lugar na escola e baseada num saber informado pela prática e pela atividade.

Vogando nos interstícios de liberdade das malhas do Estado e das corporações (Dewey, 2014), o liberalismo laboratorial deweyano apostava no enriquecimento da experiência através da ação criativa e da inovação dos arranjos institucionais. E é aqui que se reconhece a tarefa crucial da educação para Dewey: alimentar, sustentar, guiar os jovens no caminho da experimentação. Não em vista de uma revolução, pois o seu experimentalismo opõe-se à força, mas numa mudança que se vai operando pouco a pouco, por ensaio e erro.

Tanto a perspetiva normalizadora dos arranjos como a perspetiva da experimentação compartilham caraterísticas valorizadas pelo liberalismo de Dewey, e por isto mesmo reconhecem-se como perspetivas favoráveis à individuação. Contudo, ela pode combinar-se com a perspetiva da socialização, como no caso preconizado pela AE de uma das escolas

\footnotetext{
${ }^{4} \mathrm{~A}$ analogia da "paixão" pelo conhecimento político com a socialização durkheimiana torna-se evidente neste trecho retirado de uma obra de Durkheim: “Ora, não é nem com o princípio de Arquimedes nem com a regra de três que alguma vez poderemos moralizar as multidões. Só a cultura estética pode agir tão profundamente sobre as almas. Sob a influência da arte, os espíritos elevam-se, os corações aquecem, sensibilizam-se, tornam-se assim mais permeáveis uns aos outros e portanto mais aptos à vida comum" (Durkheim, 1975, p. 159).

${ }^{5} \mathrm{~A}$ este propósito é digno de nota os resultados do inquérito realizado pela OCDE, no âmbito do programa TALIS, os quais mostram que $97,5 \%$ dos professores portugueses acredita ajudar os seus estudantes a pensar criticamente, valor, de resto, muito acima dos restantes países desta organização (OECD, 2013).

${ }^{6}$ Como observa Seabra (2009, p. 75): "Historicamente, no debate dos princípios orientadores dos sistemas públicos de ensino passou-se da ideia inicial de igualdade à de equidade e a de igualdade de oportunidades foi dando lugar à de igualdade de resultados" [itálico no original].
}

(C) ETD-Educação Temática Digital Campinas, SP $\quad$ v.20 $\quad$ n.2 $\quad$ p. $413-433 \quad$ abr./jun. 2018 
acerca do direito dos alunos poderem assistir às aulas das disciplinas em atraso, combinando atitudes de prudência, de negociação, mas não uma confrontação direta com a ordem estabelecida. Já a perspetiva da experimentação poderá eventualmente adquirir contornos subjetivantes, ${ }^{7}$ mormente no que diz respeito a um retraimento da política como janela para mudar o mundo, por este não se prestar momentaneamente a uma experimentação realizável e ao alcance de um gesto, de um olhar, de uma atividade em comum.

Por fim, a perspetiva problematizadora, que nos mostra um retraimento ou uma reserva face à política clássica e uma certa indiferença face à participação associativa. Mais do que uma fuga, como no modelo de Hirschman (1970) ou uma desafeição (Magalhães, 2005), o que é suscetível de estar em causa num dado engajamento distanciado dos jovens com a política, parece ser a sua problematização, no sentido foucaultiano do termo (Gros in Foucault, 2010). Esta perspetiva, encetada nos últimos trabalhos de Foucault, compreende uma nova fase do seu pensamento político, designada por uma «política da verdade», ou por uma "política de nós mesmos», em que o objeto do reformismo se torna a relação consigo mesmo e com os outros. Nela, Foucault opera uma reviravolta quanto ao tradicional enfoque weberiano sobre a política: "para Foucault, a questão não se coloca sobre se os sujeitos consentem o poder, mas como é que o poder cria os sujeitos" (Joseph, 2004, p. 152).

Neste sentido, "Foucault não pertence nem ao campo dos detratores cínicos da democracia nem ao campo dos seus cegos aduladores. Foucault simplesmente problematizaa" (Gros in Foucault, 2010: 388). E ao retomar o estudo original dos textos antigos da época «dourada» da democracia ateniense, o pensador francês descortina "um novo modo de se envolver na política, procedendo pela problematização em vez de dogmas, contando com as capacidades éticas individuais em vez da adesão cega às doutrinas" (Voruz, 2010, p. 13).

Foucault vislumbra duas modalidades de se ser sujeito, a primeira compreende um processo de subjetificação, enquanto a segunda, um processo de subjetivação. A primeira, refere-se à livre submissão a um outro significativo, um outro que conta (Taylor, 2010), por via de uma relação de singularização direta, personalista, ao passo que a segunda se constitui como uma afirmação da singularidade própria na resistência ao poder. É nesta última apenas que, no final da subjetivação, o sujeito como consciência de si pode emergir. Da atividade do sujeito orientada por si para si provém "a escolha individual em não participar nas práticas

\footnotetext{
${ }^{7} \mathrm{O}$ carácter subjetivante refere-se às práticas de subjetivação Foucaultianas: “A subjetivação, tal como no-la apresenta o autor de Vigiar e Punir, envolve portanto exercícios de inibição do eu, ligados às dinâmicas políticas de governo e ao desenvolvimento de formas de conhecimento científico" (Ramos do Ò, 2014, p. 739).
}

(C) ETD-Educação Temática Digital Campinas, SP $\quad$ v.20 $\quad$ n.2 $\quad$ p. $413-433 \quad$ abr./jun. 2018 
que se rejeitam. Esta decisão é levada a cabo pelas práticas de si (Voruz, 2010, p. 11), as quais devem ser consideradas enquanto práticas de liberdade.

Problematizando o(s) podere(s) a que está sujeito, o sujeito resiste e coloca-o(s) à prova, arriscando falar a sua verdade (parrésia), ou então, sentindo-se coartado nas suas ações, orienta-se pelo cuidado de si (epiméleia heautoû) e opta por não participar diretamente em ações com conteúdo declaradamente político. A tarefa política da educação consiste aqui na formação de sujeitos singulares, autónomos e corajosos, arriscando falar a sua verdade, quando sentem que a democracia pode estar seriamente em causa. Desta forma, preparar os sujeitos para a política implica prepará-los para a assunção de responsabilidades e para o exercício problematizador do poder, familiarizando-os para os seus efeitos positivos e negativos.

\section{CONSIDERAÇÕES FINAIS}

A relação dos jovens estudantes com a política não deve ser apenas olhada sob o ângulo prevalecente do modelo 'económico' da sociologia da política, mas também segundo um modelo moral. O retraimento ou a indiferença pela política, a experimentação e a curiosidade em participar, uma conceção de justiça baseada na equidade ou o desejo de fazer parte de uma ordem estabelecida segundo as diferentes grandezas dos seres, representam tanto diferentes formas de ser nos engajamentos, como quadros morais de avaliação e de ação. Estes quadros morais dão conta de um domínio alargado da política enquanto experiência de relação com o mundo. Eles mostram-nos também que as perspetivas reformistas da política, exclusivamente centradas nos arranjos institucionais, são manifestamente insuficientes, pois há que ter em conta a formação das pessoas nas suas relações com o poder. A necessidade de formar melhores sujeitos políticos é hoje, aliás, face ao atual panorama político mundial, um imperativo cada vez mais premente e precioso.

Paralelamente à socialização política clássica, caracterizada fundamentalmente pela sua excessiva escolarização na preparação do jovem para o mundo, descortina-se o engajamento por individuação, caracterizado essencialmente pela participação na vida da escola e pela vontade de experimentação, e por fim, o engajamento por subjetivação, o qual se apresenta como uma problematização da política centrada, sobretudo, no aperfeiçoamento de si próprio.

O alcance desta investigação possibilita tematizar as tarefas da educação segundo os engajamentos considerados. De uma forma breve e esquemática, a trajetória de socialização recobre as preocupações tradicionais com a integração comunitária dos jovens e a solidariedade intergeracional. Considerado frequentemente como o processo por excelência 
de familiarização dos jovens com a política, centrado na narrativa e na argumentação, ele tende a invisibilizar os outros processos de relação dos jovens com o mundo.

A trajetória de individuação requer esforços na melhoria dos arranjos institucionais da organização escolar, tal como defendido por um pensador como Dewey. Ele implica uma verdadeira democratização da escola, algo ainda por fazer. Mas também incentivos à criatividade e à inovação na escola. Ao mesmo tempo que o que a trajetória de subjetivação demanda à educação, é a missão de contribuir para formar pessoas melhores com vista à constituição de uma sociedade de indivíduos. Nesta última trajetória, as reservas morais quanto a um mundo que não pode ser abraçado tal como ele é, ou as dúvidas quanto à sua transformação pela via da ação coletiva, dão lugar à crença de que o mesmo pode ser mudado por via da nossa própria mudança.

Estas tarefas educativas não são exclusivas, mas componíveis. Na verdade, todas elas têm o seu lugar no processo educativo. Elas devem constituir-se, pois, como os caminhos entrecruzados da experiência juvenil.

\section{REFERÊNCIAS}

AGUIAR, Joaquim. O discurso do eleitorado. Análise Social, Lisboa, v. 42, n. 182, p. 287-309, 2007.

ARENDT, Hanna. Verdade e política. Lisboa: Lisboa Ed., 2005.

BARDIN, Laurence. Análise de conteúdo. Lisboa: Ed. 70, 2004.

BOLTANSKI, Luc e THÉVENOT, Laurent. La justification. Les économies de la grandeur. Paris: Gallimard, 1991.

BRAUD, Philippe. La science politique. 9. ed. Paris: Puf, 2011.

CAETANO, Pedro. "A socialização política no plural". Educação e Sociedade, Campinas, Dossiê temático 1: Socialização política, v. 37, n. 137, Campinas, out. /dez., p. 1045-1060, 2016.

CANDIOTTO, Cesar. Subjetividade e verdade no último Foucault. Trans/Form/Ação, v. 31, n. 1, p. 87-103, 2008.

CASTRO, Lúcia R. (Coord.). Falatório. Participação e democracia na escola. Rio de Janeiro: Contra Capa, 2010.

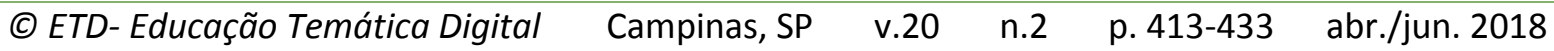


CASTRO, Lúcia e Grisolia, Felipe. Subjetivação pública ou socialização política? Sobre as articulações entre o 'político' e a infância. Educação e Sociedade, Dossiê temático 1: Socialização política, v. 37, n. 137, Campinas, out./dez., p. 971-988, 2016.

CORCUFF, Philippe. Le savant et le politique. SociologieS [En ligne], La recherche en actes, Régimes d'explication en sociologie, 2011. Disponível em http://sociologies.revues.org/353 Acesso em: 13 set. 2017.

DEWEY, John. Reconstruction in philosophy. Nova lorque: Henry Holt and Company, 1920.

DEWEY, John. Democracia e educação. Lisboa: Didáctica, 2007.

DEWEY, John. Après le libéralisme? Ses impasses, son avenir. Paris: Climats, 2014.

DURKHEIM, Émile. A ciência social e a ação. Lisboa: Bertrand, 1975.

DURKHEIM, Émile. L'éducation morale. Paris: Puf, 2012.

EUROPEAN COMISSION (EC). European Youth: Participation in Democratic Life [Report]. Flash Eurobarometer 375, mai. 2013. Disponível em http://ec.europa.eu/public opinion/flash/fl 375 en.pdf Acesso em: 13 set. 2017.

FOUCAULT, Michel. Politics, philosophy, culture. Nova lorque: Routledge, 1988.

FOUCAULT, Michel. Qu'est-ce que les Lumières? Dits et écrits, $n^{\circ} 339$, t. IV. Paris: Gallimard, 1994. p. 562-578.

FOUCAULT, Michel. Le Gouvernement de Soi et des autres. Cours au Collège de France (1982-1983). Paris: Seuil, 2008.

FOUCAULT, Michel. L'origine de l'herméneutique de soi. Conférences prononcées à Dartmouth Collège, 1980. Paris: Vrin, 2013.

FUJITA, Kojiro. Pour une philosophie de la subjectivation. Étude sur Michel Foucault. Université Paris-Est. Thèse de Doctorat [em linha], 2015. Disponível em https://tel.archivesouvertes.fr/tel-01304072 Acesso em: 13 set. 2017.

GARNIER, Pascale. La socialisation en procès: conflits, enjeux et dynamiques. VEI Enjeux, no 120, p. 9-17, 2010. Disponível em: http://www2.cndp.fr/revueVEl/120/garnier120.pdf Acesso em: 13 dez. 2017.

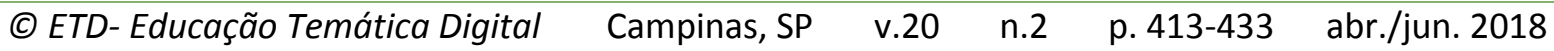


GROS, Frédéric. Course context. In M. Foucault, The Government of Self and Others Michel Foucault: Lectures at the Collège de France, 1982-1983. Basingstoke: Palgrave MacMillan, 2010. P.377-391.

HIRSCHMAN, Albert O. Exit, voice, and loyalty: responses to decline in firms, organizations, and states. Cambridge, Mass.: Harvard Univ., 1970.

JOSEPH, Jonathan. Foucault and reality. Capital and Class, n. 82, p. 143-165, 2004.

KANT, Immanuel. Réponse à la question «Qu'est-ce que les Lumières?». Disponível: https://philosophie.cegeptr.qc.ca/wp-content/documents/Quest-ce-que-lesLumi\%C3\%A8res\%EF\%80\%A5-1784.pdf Acesso em: 13 set. 2017.

LIMA, L. (Dir.). Por Favor, elejam a B. O Associativismo Estudantil na escola secundária. Lisboa: Fundação Calouste Gulbenkian, 1998.

LIMA, Maria da P. C. e ARTILES, Antonio M. Descontentamento na Europa em tempos de austeridade: da ação coletiva à participação individual no protesto social. Revista Crítica de Ciências Sociais, Coimbra, n. 103, p. 137-172, 2014.

LISI, M., MARCHI, R., e EVANS, A. M. Participação política e qualidade da democracia. In A. C. Pinto, L. de Sousa e P. C. Magalhães (Orgs.), A qualidade da democracia em Portugal: a Visão dos Cidadãos. Lisboa, Instituto de Ciências Sociais da Universidade de Lisboa, 2013. p.51-77.

LOBO, M. C., FERREIRA, V. S., ROWLAND, J. Emprego, mobilidade e lazer: situações e atitudes dos jovens portugueses numa perspectiva comparada. Lisboa: Instituto de Ciências Sociais da Universidade de Lisboa, 2015.

LOPES, João T. Tristes escolas. Práticas culturais estudantis no espaço escolar urbano. Porto: Afrontamento, 1997.

MAGALHÃES, Pedro C. Disaffected democrats: political attitudes and political action in Portugal. West European Politics, v. 28, n. 5, p. 973-991, 2005.

MAGALHÃES, Pedro C., MORAL, Jesus. Os jovens e a política. Um estudo para a presidência da República. Lisboa: Universidade Católica Portuguesa/CESOP, 2008.

OECD. Teachers and teaching conditions. Teaching and Learning International Survey (TALIS), 2013. Disponível em:

http://gpseducation.oecd.org/CountryProfile?primaryCountry=PRT\&treshold=10\&topic=TA A Acesso em 15 set.2017

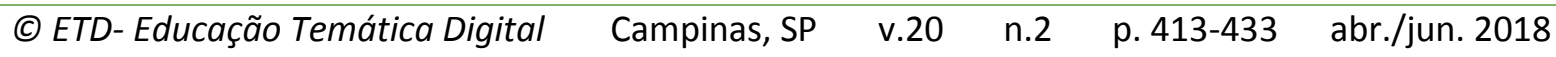


PAIS, José Machado. Consciência histórica e identidade. Oeiras: Celta, 1999.

RAMOS DO Ó, Jorge. Questionando o social. Governamentalidade, tecnologias do eu e a história da escola. Análise Social, v. 212, xlix, p. 737-742, 2014.

RESENDE, José Manuel. A sociedade contra a escola? A socialização política escolar num contexto de incerteza. Lisboa: Instituto Piaget, 2010.

RICCEUR, Paul. Parcours de la reconnaissance. Paris: Éditions Stock, 2004.

SARDINHA, Diogo. Kant, Foucault e a antropologia pragmática. Kant e-Prints. Campinas, Série 2, v. 6, n. 2, p. 43-58, 2011.

SARTORI, Giovanni. From the Sociology of Politics to Political Sociology. Government and Opposition, n. 4, p. 195-214, 1969.

SEABRA, Teresa. Desigualdades escolares e desigualdades sociais. Sociologia, Problemas e Práticas, n. 59, p. 75-106, 2009.

SIMMEL, Geörg. Sociologie. Études sur les formes de la socialisation. Paris: Puf, 1999.

TAYLOR, Charles. Imaginários sociais modernos. Lisboa: Texto \& Grafia, 2010.

THÉVENOT, Laurent. L'action au pluriel. Sociologie des régimes d'engagement. Paris: La Découverte, 2006.

VARELA, Alexandre M. R. Jovens e política: o papel da socialização na participação política. Tese de Mestrado, Lisboa: ISCTE, 2009. Disponível em http://hdl.handle.net/10071/1804 Acesso em: 13 set. 2017.

VIEIRA, M. M., FERREIRA, V. S., ROWLAND, J. Retrato da juventude em Portugal: traços e tendências nos censos de 2001 e 2011. Revista de Estudos Demográficos, n. 54, p. 5-25, 2015.

VORUZ, Veronique. Politics in Foucault's later work: a philosophy of truth; or reformism in question. Theoretical Criminology, v. 15, n. 1, p. 1-19, 2010.

WEBER, Max. A política como vocação. In H. H. Gerth e C. W. Mills, (Org.), Max Weber Ensaios de Sociologia. Rio de Janeiro: Livros Técnicos e Científicos, 1967. p. 55-89.

Revisor do artigo - Manuela Mendes mamendesster@gmail.com

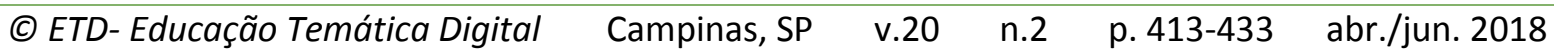

